\title{
BMJ Open Mindfulness online: an evaluation of the feasibility of a web-based mindfulness course for stress, anxiety and depression
}

\author{
Adele Krusche, ${ }^{1}$ Eva Cyhlarova, ${ }^{2}$ J Mark G Williams ${ }^{1}$
}

To cite: Krusche A, Cyhlarova E, Williams JMG. Mindfulness online: an evaluation

of the feasibility of a webbased mindfulness course for stress,

anxiety and depression. BMJ Open 2013;3:e003498. doi:10.1136/bmjopen-2013003498

- Prepublication history and additional material for this paper is available online. To view these files please visit the journal online (http://dx.doi.org/10.1136/ bmjopen-2013-003498).

Received 28 June 2013 Revised 2 October 2013 Accepted 3 October 2013

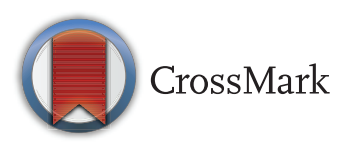

${ }^{1}$ Department of Psychiatry, University of Oxford, Oxford, UK

${ }^{2}$ Mental Health Foundation, London, UK

Correspondence to Adele Krusche; adele. krusche@psych.ox.ac.uk

\section{ABSTRACT}

Objectives: Face-to-face mindfulness interventions have been shown to significantly decrease perceived stress, anxiety and depression and research is beginning to show similar benefits for such courses delivered via the internet. We investigated the feasibility and effectiveness of an online mindfulness course for perceived stress, anxiety and depression.

Design: A follow-up investigation of an online mindfulness course. Previous research examining the change in perceived stress showed promising results.

Measures of anxiety and depression were added to the online mindfulness course and these were investigated as well as perceived stress using a new, larger sample. Participants: Participants ( $\mathrm{N}=273$ ) were self-referrals to the online course who completed the outcome measure immediately before the course, upon course completion and at 1 month follow-up.

Intervention: The programme consists of 10 sessions, guided meditation videos and automated emails, with elements of Mindfulness-Based Stress Reduction and Mindfulness-Based Cognitive Therapy, completed at a pace to suit the individual (minimum length 4 weeks).

Primary and secondary outcome measures: The Perceived Stress Scale, the Generalised Anxiety Disorder Assessment-7 and the Patient Health Questionnaire-9 (for depression). Mindfulness practice was self-reported at automated time points upon login, once the exercises and sessions for each week were completed.

Results: Perceived stress, anxiety and depression significantly decreased at course completion and further decreased at 1 month follow-up, with effect sizes comparable to those found with face-to-face and other online mindfulness courses and to other types of intervention, such as cognitive behavioural therapy for stress. The amount of meditation practice reported did affect outcome when controlling for baseline severity.

Conclusions: The online mindfulness course appears to be an acceptable, accessible intervention which reduces stress, anxiety and depression. However, there is no control comparison and future research is required to assess the effects of the course for different samples.

\section{Strengths and limitations of this study}

- A large sample was used and consisted of actual service users who took part in the course without request, and who agreed for their data to be anonymously analysed for research.

- More mindfulness practice resulted in better outcomes when controlling for baseline severity. This warrants further investigation, as self-report practice logs may have been unreliable.

- There was no control group, so it is unclear whether the course contributed to a decrease in negative symptoms or whether this was due to regression to the mean.

\section{INTRODUCTION}

Depression is a common and disabling condition affecting an estimated $8-12 \%$ of the population in Britain in a year. ${ }^{1}$ The prevalence of the condition generates large healthcare costs as well as severely lowering the quality of life for the individual. ${ }^{2}$ It is estimated that the Improving Access to Psychological Therapies programme (IAPT) service for depression costs, on average, $£ 1190$ per person. ${ }^{3}$ Depression and anxiety are commonly comorbid. ${ }^{4}$ Indeed, mixed depression and anxiety is the most common mental disorder in Britain with $10 \%$ of the respondents to the Office for National Statistics 2001 Psychiatric Morbidity survey indicating that they had these symptoms. ${ }^{1}$ Survey respondents also reported rates of 19$29 \%$ for worry. Maintained worrisome thoughts and stress can have a number of physical and mental negative effects ${ }^{5-7}$ and have often been linked to general anxiety, ${ }^{8}$ anxiety disorders ${ }^{5}$ and depression, both in terms of onset ${ }^{89}$ and recovery time. ${ }^{4}$

There is increasing research showing that mindfulness-based courses, particularly mindfulness-based stress reduction (MBSR) ${ }^{10} 11$ and mindfulness-based cognitive therapy 
$(\mathrm{MBCT})^{12}$ are effective interventions for a broad range of health problems. ${ }^{13-15}$ Mindfulness interventions have been shown as effective for recurrent depression, reducing relapse rates and antidepressant usage ${ }^{12} 16-18$ and for reducing anxiety. ${ }^{15}{ }^{19}$ Research also shows that perceived stress decreases following participation in a mindfulness intervention, with the decrease maintained at follow-up (between 1 and 3 months).$^{20-23}$

Although there are helpful interventions available for stress, anxiety and depression, it has been observed that the National Health Service (NHS) cannot handle the need for mental health resources in the UK. ${ }^{324}$ The availability of mindfulness courses across the UK is variable, with lengthy NHS waiting lists only serving certain health problems, such as recurrent depression or chronic fatigue syndrome. Private courses can be expensive, ranging between $£ 200$ and $£ 350$. There are numerous other reasons why people may be unable to attend a course such as disability, childcare, course location and the times that the courses are available. ${ }^{25}{ }^{26}$ Online interventions are being created and studied to provide helpful mental health resources which may be inaccessible otherwise. By offering treatment via the internet, providers are delivering interventions with reduced cost to the health services and patients ${ }^{27} 28$ and allowing the provision for patients to complete courses in their own comfortable, familiar surroundings. ${ }^{25} 26$

Several trials of online Cognitive Behavioural Therapy (CBT) and stress management look promising for a range of issues, including stress, ${ }^{29}{ }^{30}$ anxiety $^{28}{ }^{31}$ and depression, ${ }^{28}{ }^{31-36}$ reducing relapse rates, recurrence and antidepressant usage. This is particularly the case for longer courses and for users who engage most with the programmes. ${ }^{27} 35$ Participants who are more familiar with computers, more comfortable in their surroundings, prefer therapy to be anonymous and visit the intervention website more often seem to benefit most from an online course. ${ }^{26}{ }^{35}$ Computerised CBT with therapist support has also become part of the intervention for IAPT Step 2 services for patients with moderate depression with positive results for depression and anxiety. ${ }^{3}$

There is growing evidence for online mindfulness courses being as effective as other face-to-face interventions and online courses for stress even without a therapeutic alliance. ${ }^{37-40}$ Previously found Perceived Stress Scale (PSS) effect sizes are comparable to those found with face-to-face mindfulness and CBT interventions, including our previous research examining the course currently under investigation. ${ }^{40-42}$ One RCT found that an automated internet-based therapy including CBT and mindfulness actually had better outcomes for Irritable Bowel Syndrome (IBS) than the comparative online therapist-led intervention, suggesting that the effects of internet interventions cannot be attributed to, and do not rely on, therapist interaction. ${ }^{43}$ Studies are finding that online mindfulness courses can be beneficial for depression in samples with IBS and epilepsy and anxiety symptoms in a non-clinical sample comparing a 3-week mindfulness course with positive psychology interventions and treatment as usual (see Monshat ${ }^{38}$ for a review). Although previous studies have found that an online mindfulness course can decrease anxiety and depressive symptoms, so far no research has examined the change in a non-clinical sample using an online mindfulness course based directly on MBSR and MBCT courses. This study presents a follow-up of our earlier study on an online mindfulness course that examined change in perceived stress. ${ }^{41}$ It extends our previous study by examining the effect of the course on depression and anxiety symptoms, benchmarking the effects against other studies by using measures that are now widely used in primary care practices in the UK. More significantly, these measures are used in the IAPT initiative, a major roll-out project in England that supports the NHS in implementing National Institute for Health and Clinical Excellence (NICE) guidelines for people suffering from depression and anxiety disorders by offering a realistic and routine first-line treatment.

Although the mechanisms of change at work in mindfulness interventions are unclear, many researchers agree that the meditation practices taught during mindfulness courses cultivate awareness and acceptance, which lower levels of anxiety, depression and stress. ${ }^{44}$ This seems logical when a greater level of trait mindfulness equates to lower levels of stress ${ }^{45}$ and when larger amounts of practice increase trait mindfulness and decrease low mood. ${ }^{20}$ However, there are mixed results when investigating the amount of mindfulness practice as a mediator of change. Other investigations of face-to-face mindfulness courses ${ }^{20} 46$ and an online course $^{37}$ have reported that a greater amount of meditation practice is associated with greater decreases in stress, but we did not find this in our preliminary investigation. ${ }^{41}$ The study gives the opportunity to re-examine whether the amount of practice mediates degree of change in outcome, using a larger sample size where it should be easier to detect a significant effect if it is present.

The hypotheses are (1) that perceived stress, anxiety and depression will significantly decrease at course completion, (2) that the decrease will be maintained at follow-up; that is, the size of the change at follow-up will remain significantly different from pretest levels, (3) that participants who practice more will have a larger decrease in negative mood and (4) that the decrease will be comparable to other types of intervention. The time taken to complete the course will also be explored for any effect on the outcomes.

\section{METHOD}

\section{Participants}

Study participants were self-referrals to an online mindfulness course. Participation in the online course was on a self-pay basis. Self-report data were collected prior to the start of the course and there was an opportunity to 
give feedback 1 month after course completion. Consent for participant data to be used for course audit and research was taken when registering for the online course as part of the terms and conditions (see online supplementary appendix 1).

\section{Procedure}

The online intervention was a modified mindfulness course comprising elements of MBSR and MBCT. The online course costs $£ 60$ ( US $\$ 90)$, and follows the same class sequence as the 8-week mindfulness course. The course is run by the Mental Health Foundation and Wellmind Media and was developed in conjunction with leading UK mindfulness instructors. The participants access instructional videos which guide the formal meditations through the website (http://www. bemindfulonline.co.uk).

The online course consists of 10 interactive sessions led by two mindfulness instructors, one male and one female. Participants learn to use formal meditation skills (body scan, mindful movement, sitting meditation, 3 minute breathing space) and informal mindfulness techniques (incorporating mindfulness into daily activities, such as mindful eating) through videos, assignments and emails. The course lasts for a minimum of 4 weeks, depending on when participants are able to complete the practice and homework logs. Participants are able to have a break from the course and receive email reminders to continue from the point at which they last participated.

Participants were asked to practice one formal meditation exercise using the audio and video clips supplied and one informal practice every day of the week (or as much as they can), plus one extra practice or task. For example, during week 1 participants are guided in the use of the body scan and asked to practice this during the following week as well as eating a meal 'mindfully' and bringing awareness to a chosen activity, such as brushing teeth. There was no contact with a mindfulness teacher or other course participants.

\section{Measures}

Perceived stress using the PSS, ${ }^{47}$ anxiety using the Generalised Anxiety Disorder Assessment (GAD-7) ${ }^{48}$ and depression using the Patient Health Questionnaire (PHQ-9) ${ }^{49}$ were measured before the course, immediately on completion and at 1 month follow-up.

\section{Perceived stress}

The Perceived Stress Scale (PSS) ${ }^{47}$ is a widely used and validated scale which measures how much the individual perceives events as uncontrollable and overwhelming during the previous month. The PSS consists of 10 items using five-point scales, each ranging from 0 to 4 , with 4 being the highest stress score and total scores ranging from 0 to 40 . The predictive validity is expected to change after 4 to 8 weeks because of the varying nature of life events and daily worries and their effect on perceived stress. The PSS has been shown to have good reliability and validity, and has been used in previous research of mindfulness. Several studies using a mindfulness intervention have reported a reduction in PSS scores $^{2021233740-4250}$ (see Krusche et al ${ }^{41}$ for a detailed compilation of mindfulness studies and their effects on perceived stress). In this study, the PSS was used before the intervention, immediately after completing the final practice $\log$ and at 1 month follow-up; Cronbach's $\alpha$ was 0.79 .

\section{Anxiety}

The General Anxiety Disorder 7-item Scale (GAD-7 $)^{48}$ is widely used to assess anxiety during the preceding 2 weeks and has been shown to have good reliability and validity. ${ }^{51}{ }^{52}$ The GAD-7 consists of seven items answered using a four-point scale, ranging from 0 to 3 with total scores ranging from 0 to 21 . Higher scores indicate increasing functional impairment with cut-offs at 5, 10 and 15 for mild, moderate and severe anxiety, respectively. ${ }^{48} 53$ The GAD-7 has been used in previous mindfulness intervention research showing a reduction after a face-to-face course ${ }^{15}$; however, it has not been used to evaluate an online course. The GAD-7 is utilised by IAPT services to assess the efficacy of their interventions for anxiety and depression and has shown a reduction at follow-up. ${ }^{3}$ Anxiety was assessed before the intervention, on course completion and at 1 month follow-up; Cronbach's $\alpha$ for the GAD-7 was 0.71 .

\section{Depression}

The Patient Health Questionnaire (PHQ-9) ${ }^{49}$ is a widely used and validated scale used to assess depression severity during the preceding 2 weeks. ${ }^{52} 5455$ The PHQ-9 consists of 9 items answered using a four-point scale, ranging from 0 to 3, and a further item asking about the level of difficulty associated with any checked off items. Scores range from 0 to 27 with cut-off points for depression at 5, 10, 15 and 20 for mild, moderate, moderately severe and severe depression, respectively. ${ }^{49}$ The PHQ-9 has been shown to have good reliability and validity, has been used in previous research investigating mindfulness interventions and has been shown to reduce following treatment. ${ }^{15} 5657$ IAPT services use the PHQ-9 to assess the efficacy of their interventions for anxiety and depression with a reduction in scores at follow-up. ${ }^{3}$ The PHQ-9 has also shown a decrease when used to evaluate an online CBT course for depression $^{27} 36$ but has not been used to evaluate an online mindfulness course. Depression was assessed before the intervention, on course completion and at 1 month follow-up; Cronbach's $\alpha$ for the PHQ-9 was 0.73.

\section{Mindfulness practice}

The amount of weekly mindfulness practice was determined by self-report. Participants were asked to complete three practice questions each week (12 in total). The first question concerned frequency of formal practice (Every Day, Most Days, Once or Twice, and Never), the second, 
informal practice (Yes/Always, Sometimes, No) and the third, another practice for the week, for example, bringing attention to a chosen activity (Every Time, Most Times, Once or a Few Times, or Never). For analysis, practice scores were calculated for formal practice on a scale from 1 (Every Day) to 4 (Never). Informal practice responses were converted in the same way where 1 was 'Yes' or 'Always', 3 was 'Sometimes' and 4 was 'No' or 'Never'. Practice scores were averaged across informal and formal practice and across weeks 1 to 4 , producing a mean practice score ranging between 1 and 4, with 1 equating to the participant practicing as much as possible and 4 equating to no practice. Participants were grouped according to level of practice into those who practiced 0 to 2 (Every Day or Most Days), 2.01 to 3 (Sometimes) and 3.01 to 4 (Rarely or Never). Participants who did not report their practice were assumed not to have completed any meditation exercises or tasks for that week.

The completion time of the course was calculated using the start and finish dates. Participants were separated into two groups to compare outcomes in relation to the time taken to complete the course. The online course is designed to take 4 weeks, but can be paused and restarted at will. The two groups for analysis were 0 7 weeks completion time $(n=163)$ and more than 7 weeks completion time $(\mathrm{n}=110)$.

\section{RESULTS}

\section{Sample characteristics}

Data from 273 participants who completed the course, including the 1 month follow-up, were analysed. This sample only includes completers and drop-out rates are not reported; however, at the time of publication, $29 \%$ of people starting the course had completed it and the 1 month follow-up (1497 people had completed the course and follow-up out of 5094 people who had signed up to the course from November 2010 to August 2013). The mean age of the participants was 47.7 years (SD 11.98, range 20-80), and $78 \%$ were female. The mean time to finish the course was 7.06 weeks; the mode completion time was 4.14 weeks. The majority of the sample $(235,86.08 \%)$ completed all 12 of the selfreport practice questions. 31 (11.36\%) participants completed eight or more of the practice questions and seven participants $(2.56 \%)$ completed six or less practice questions, of which two completed zero. There were no significant differences in age; time taken to complete the course, PSS, GAD-7 or PHQ-9 scores at any time point between those who completed the practice questions and those who did not; the course completion time for participants who completed less than half the practice questions was 4.5 weeks.

\section{Stress, anxiety and depression at baseline}

The mean baseline PSS score for the sample was 23.04 (SD 6.85, range 1-40), which is higher than that provided in published population norms (between 11.9 and
14.7).$^{58}$ Indeed, the average PSS score of this sample was comparable to previous samples of either 'highly stressed' individuals ${ }^{59}$ or individuals with a wide range of illness, personal or employment-related stress. ${ }^{20}$

The mean baseline GAD-7 score for the sample was 10.98 (SD 5.17, range 0-21), which is higher than the published normative population scores (between 2.7 and 3.8). ${ }^{5160}$ The score was in the published range for moderate anxiety ${ }^{48}{ }^{53}$ and as high as scores published assessing a sample of people with Generalised Anxiety Disorder. ${ }^{61}$ Baseline anxiety was lower than the baseline scores of people seeking treatment through IAPT for depression and anxiety $(13.86)^{3}$.

The mean baseline PHQ-9 score for the sample was 10.06 (SD 6.40, range 0-27), which is higher than population norms $(3.3)^{49}$ and lower than baseline scores of those seeking treatment for depression and anxiety through IAPT $(16.44)^{3}$. The score was in the published range for moderate depression. ${ }^{49}$

\section{Changes in perceived stress}

The changes in mean PSS score from before to after the course and at 1 month follow-up are shown in figure 1 . The mean PSS score of the sample prior to the course was 23.04 (SD 6.85, range 1-40). The mean PSS score after the online mindfulness course was 15.06 (SD 6.42, range 0-36) and at 1 month follow-up 13.45 (SD 6.99, range 0-37). A repeated measures ANOVA indicated that there was a significant decrease from precourse to postcourse $(\mathrm{F}(1.86,506.97)=357.89, \mathrm{p}<0.001)^{1}$, and post hoc tests using the Bonferroni correction revealed that that PSS score further decreased significantly from postcourse to 1 month follow-up, mean difference from postcourse to follow-up 1.612, standard error 0.348, $\mathrm{p}<0.001$. The pre-post effect size (d) was 1.20, and pre-follow-up was 1.39 , comparable to other published studies of mindfulness courses delivered in face-to-face groups 20212350 and online. ${ }^{3740-42}$ The effect size is also comparable to those found with CBT delivered in person ${ }^{62}$ and only slightly less effective than an internet-based stress management for a more severely stressed sample. ${ }^{29}$ Postcourse to follow-up effect size was 0.24 .

\section{Changes in anxiety}

The changes in mean GAD-7 before and after the course and after 1 month follow-up are shown in figure 2. The mean GAD-7 score of the sample prior to the course was 10.98 (SD 5.17, range 0-21). The mean GAD-7 score after the online mindfulness course was 5.45 (SD 3.77, range 0-19) and at 1 month follow-up 4.60 (SD 3.72, range 0-21). A repeated measures ANOVA indicated that the mean GAD-7 score changed significantly precourse to postcourse $(\mathrm{F}(1.71,465.4)$ $=325.53, \quad \mathrm{p}<0.001)^{2}$ and post hoc tests using the Bonferroni correction revealed that GAD-7 score also further significantly decreased at 1 month follow-up, mean difference post to follow-up 0.850, standard error $0.211, \mathrm{p}<0.001$. The pre-post effect size (d) was 1.22 , 


\section{Change in Perceived Stress from Pre to Post-course and Follow-up (one month after course completion).}

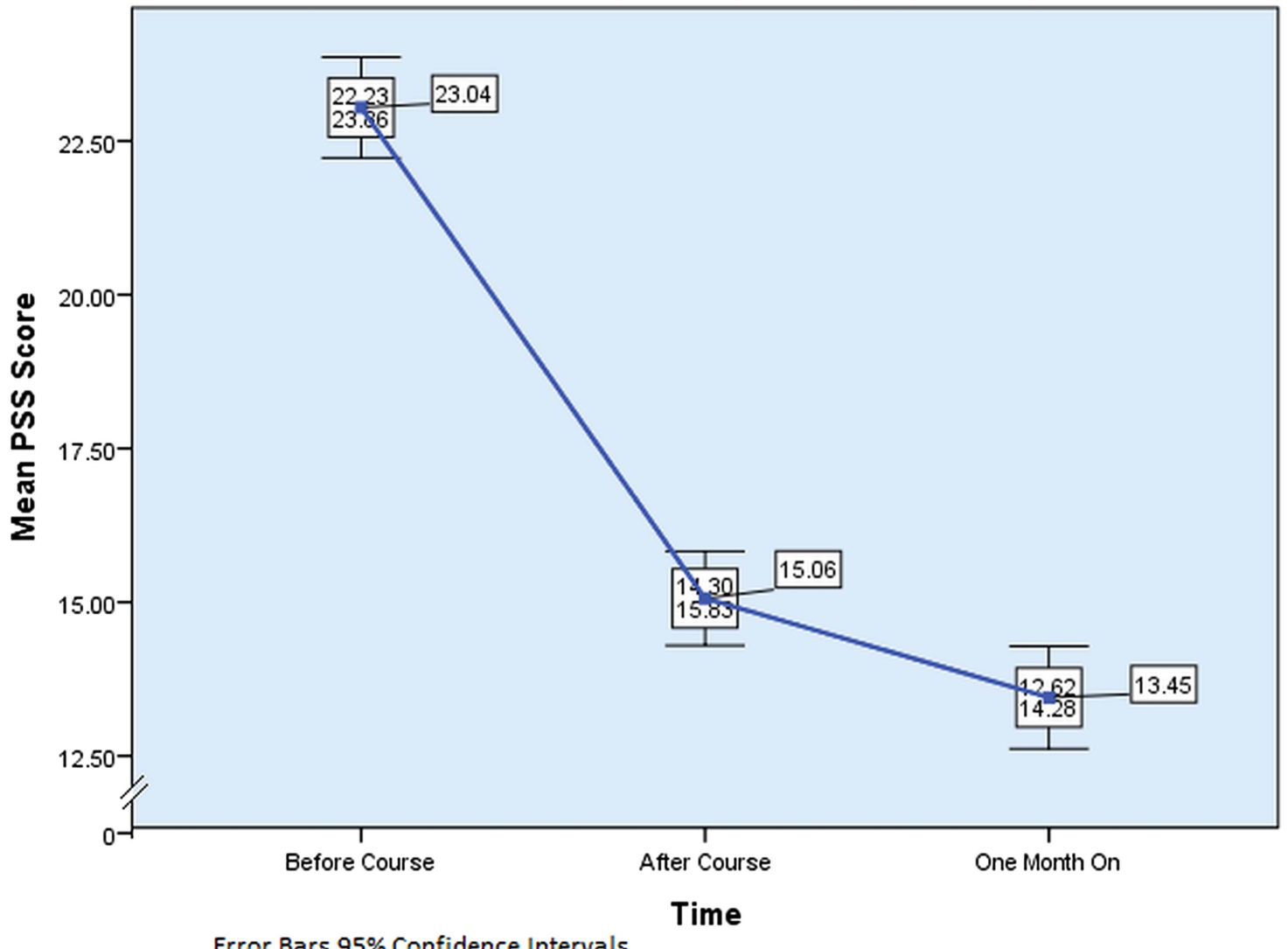

Error Bars 95\% Confidence Intervals

Figure 1 Change in perceived stress from precourse to postcourse and follow-up (1 month after course completion).

and pre-follow-up was 1.42 , comparable to other published studies of online CBT to improve well-being in the general population, ${ }^{28}$ a Acceptance-Based Behaviour Therapy (ABBT) for Generalized Anxiety Disorder delivered in person ${ }^{61}$ and mindfulness courses delivered in person. ${ }^{15}$ The change in anxiety is higher than effect sizes found for IAPT depression and anxiety treatment where follow-up was at 4 and 8 months $(0.47$ and 0.65 , respectively) $;^{3}$ however, the sample baseline was also lower than those found with IAPT. Postcourse to follow-up effect size was 0.23 , similar to other online CBT outcomes. $^{28}$

\section{Changes in depression}

The changes in mean PHQ-9 before and after the course and after 1 month follow-up are shown in figure 3. The mean PHQ-9 score of the sample prior to the course was 10.06 (SD 6.40, range 0-27). The mean PHQ-9 score after the online mindfulness course was 5.04 (SD 3.84, range 0-24) and at 1 month follow-up 4.30 (SD 3.97, range 0-23). A repeated measures ANOVA indicated that the mean PHQ-9 score changed significantly precourse to postcourse $(\mathrm{F}(1.51,409.9)=$ 215.35, $\mathrm{p}<0.001)^{3}$ and additionally, post hoc tests using the Bonferroni correction indicated that PHQ-9 score also further significantly decreased at 1 month follow-up, mean difference post to follow-up 0.744, standard error 0.202, $\mathrm{p}<0.005$. The pre-post effect size $(\mathrm{d})$ was 0.95 , and pre-follow-up was 1.08 , comparable to effect sizes published investigating face-to-face mindfulness interventions for depressive symptoms in those with diabetes, PTSD and cancer $^{15} 5657$ and online cognitive therapy interventions for depressive symptoms in a moderately depressed sample. ${ }^{27} 36$ The change in PHQ-9 is higher than effect sizes found for IAPT depression and anxiety treatment where follow-up was at 4 and 8 months $(0.46 \text { and } 0.63 \text {, respectively })^{3}$ where the IAPT sample started with higher baseline depression scores. Postcourse to follow-up effect size was 0.19 .

\section{Mindfulness practice}

The amount of total average practice was significantly correlated with PSS, GAD-7 and PHQ-9 levels at follow-up $(\mathrm{r}=0.16, \mathrm{p}<0.001, \mathrm{r}=0.14, \mathrm{p}<0.05$ and $\mathrm{r}=0.13$, $\mathrm{p}<0.05$ ) but not with the amount of change in negative mood. Furthermore, when practice was divided into 'formal' (eg, body-scan and sitting meditations) and 'informal' (eg, mindful meal and stress awareness) practice, significant correlations were found only with informal practice and PSS ( $\mathrm{r}=0.16, \mathrm{p}<0.001$, GAD-7, $\mathrm{r}=0.13$, 


\section{Change in Anxiety from Pre to Post-course and Follow-up (one month after course completion).}

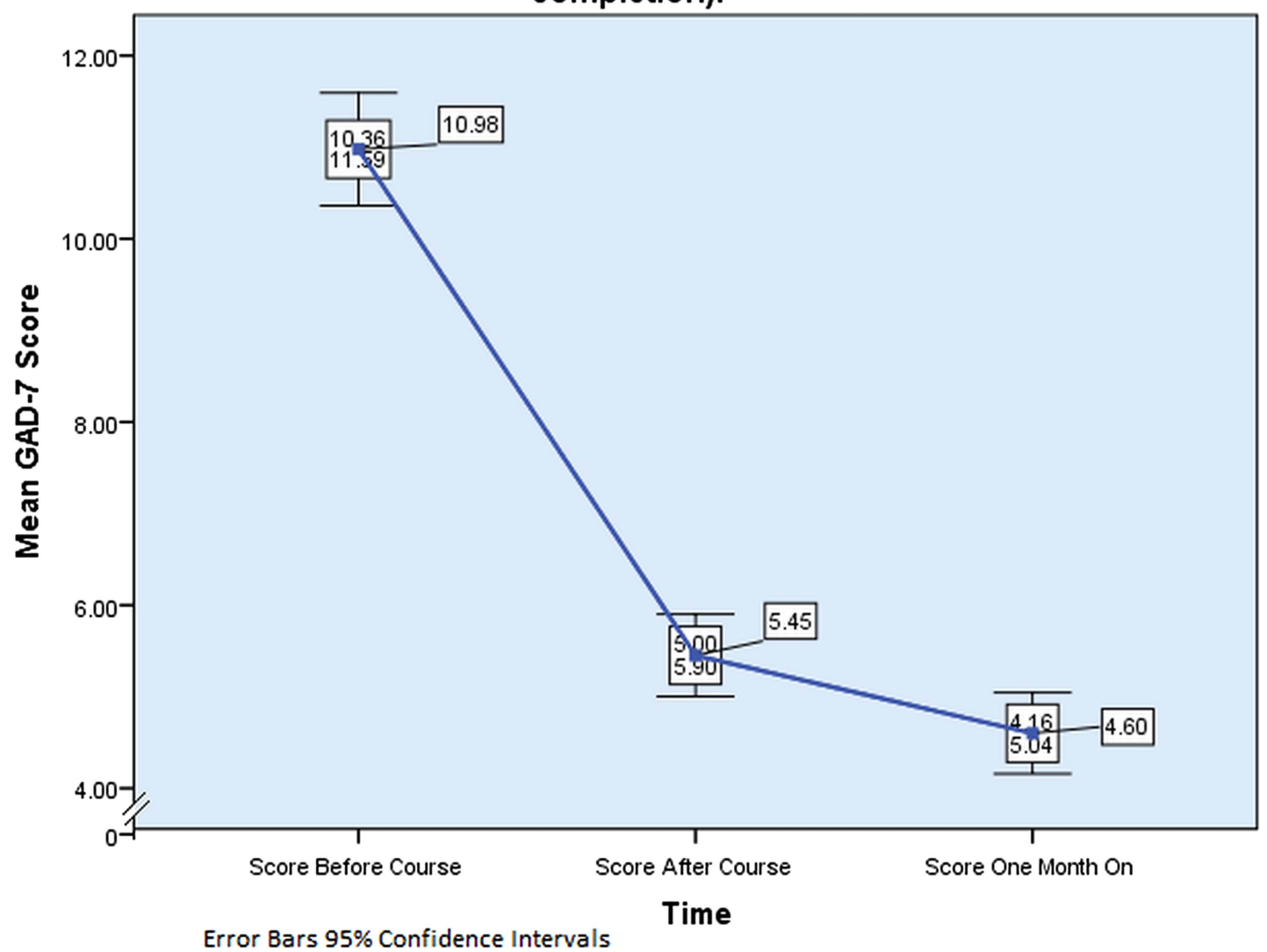

Figure 2 Change in anxiety from precourse to postcourse and follow-up (1 month after course completion).

$\mathrm{p}<0.05$ and $\mathrm{PHQ}-9, \mathrm{r}=0.17, \mathrm{p}<0.001)$. In all cases, however, the absolute magnitude of these associations was small.

The sample was divided into three groups according to the amount of practice: high ('Every Day or Most Days' $n=112$ ), moderate ('Sometimes' $n=141$ ) and low ('Rarely or Never' $n=20$ ). A repeated-measures ANOVA showed no significant difference between the practice groups in their PSS, GAD-7 or PHQ-9 decrease. It was found, however, that the low practice group had higher PSS $(\mathrm{F}(2,270)=255.89, \mathrm{p}<0.001)$ GAD-7 $(\mathrm{F}(2,270)=205.9$, $\mathrm{p}<0.001)$ and PHQ-9 $(\mathrm{F}(2,270)=122.6, \mathrm{p}<0.001)$ scores at baseline. Partial correlations revealed that the grouped average practice variable was not significantly correlated with the change from pre to post when controlling for baseline severity; however, average practice as a continuous variable was correlated with change in PSS $(r=$ $-0.122, \mathrm{p}<0.05$, GAD-7, $\mathrm{r}=-0.128, \mathrm{p}<0.05$ and PHQ-9, $\mathrm{r}=$ $-0.138, \mathrm{p}<0.05)$.

Multiple regression analysis was used to test if mindfulness practice significantly predicted the change in participants' PSS, GAD-7 and PHQ-9 outcomes when controlling for baseline severity. Baseline PSS score $(\beta=0.457, \mathrm{p}<0.001)$ and amount of practice $(\beta=-1.148, \mathrm{p}<0.05)$ were significant predictors of the change in PSS $\left(\mathrm{R}^{2}=0.27, \mathrm{~F}(2,270)\right.$ $=50.69, \mathrm{p}<0.001)$; baseline GAD-7 score $(\beta=0.644, \mathrm{p}<0.001)$ and amount of practice $(\beta=-0.848, \mathrm{p}<0.05)$ were significant predictors of the change in GAD-7 score $\left(\mathrm{R}^{2}=0.52\right.$, $\mathrm{F}(2,270)=144.45, \mathrm{p}<0.001)$; and baseline PHQ-9 score $(\beta=0.668, p<0.001)$ and amount of practice $(\beta=-0.861$, $\mathrm{p}<0.05)$ were significant predictors of the change in PHQ-9 $\left(\mathrm{R}^{2}=0.65, \mathrm{~F}(2,270)=250.31, \mathrm{p}<0.001\right)$. Controlling for baseline severity, when more practice was reported, there was a larger change in pre to post outcome.

\section{Course completion time}

The sample was divided into two groups, 0-7 and 7.01 weeks or more completion time, to examine whether course completion time affected PSS, GAD-7 and PHQ-9 scores. A repeated-measures ANOVA showed no significant difference. However, a $\chi^{2}$ analysis was conducted on completion time and mindfulness practice and it was found that the more time taken to complete the course, the less practice was reported by participants $\left(\chi^{2}=9.74, \quad \mathrm{df}=2, \mathrm{p}<0.001\right)$. Regression analysis, using weeks as a continuous variable, revealed that longer course time in weeks $(\beta=-0.165, \mathrm{p}<0.05)$ was a predictor of lesser change in PSS $\left(\mathrm{R}^{2}=0.12, \quad \mathrm{~F}(1,271)=4.23\right.$, $\mathrm{p}<0.05)$, that longer course time $(\beta=-0.191, \mathrm{p}<0.005)$ predicted lesser GAD-7 change $\left(\mathrm{R}^{2}=0.18, \mathrm{~F}(1,271)=9.57\right.$, $\mathrm{p}<0.005)$ and longer course time $(\beta=-0.173, \mathrm{p}<0.05)$ also 


\section{Change in Depression from Pre to Post-course and Follow-up (one month after course completion).}

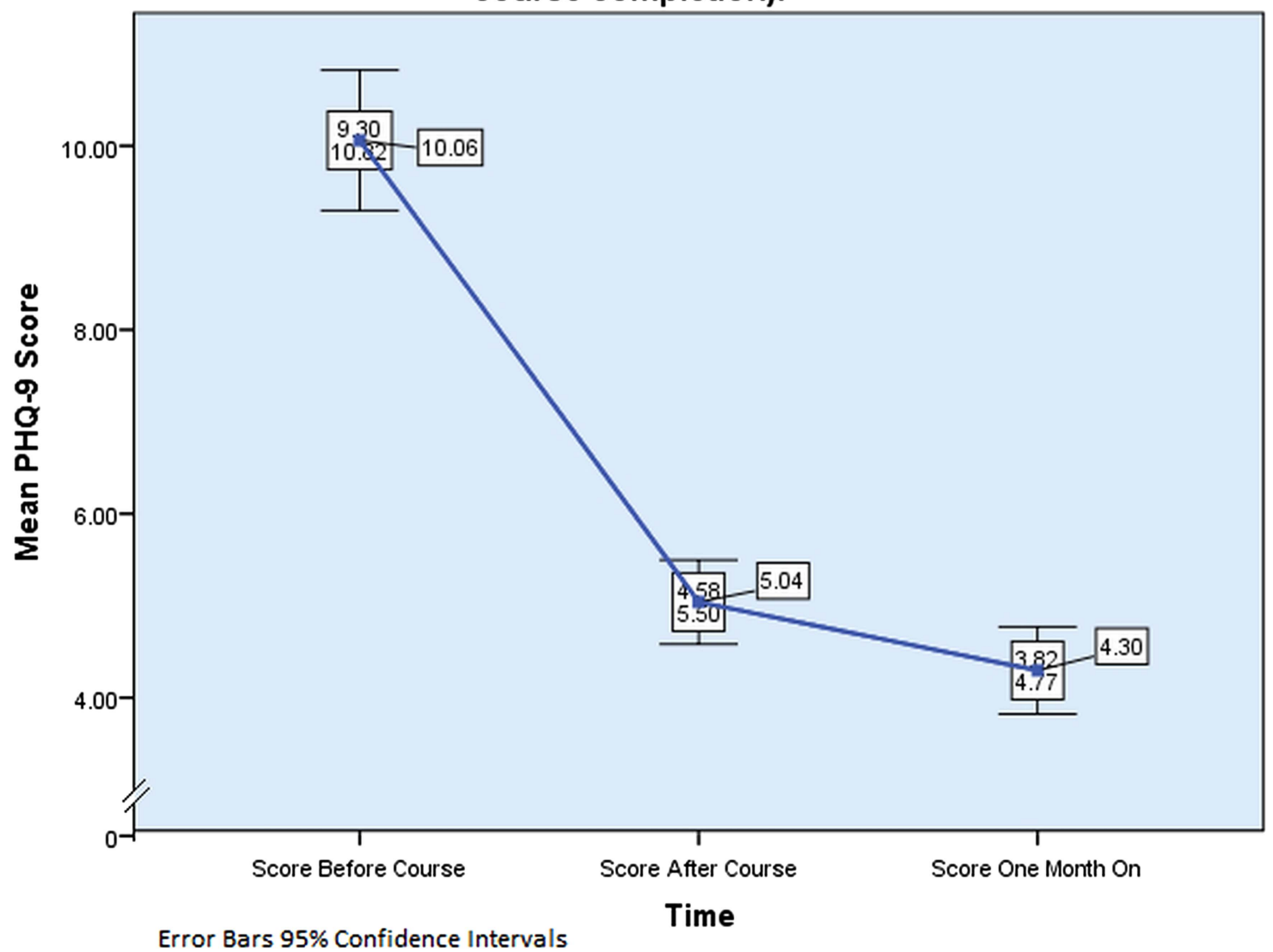

Figure 3 Change in depression from precourse to postcourse and follow-up (1 month after course completion).

predicted lesser PHQ-9 score change $\left(\mathrm{R}^{2}=0.14\right.$, $\mathrm{F}(1,271)=5.98, \mathrm{p}<0.05)$.

1. Maulchy's test indicated that the assumption of sphericity had been violated: $\chi^{2}(2)=20.56, \mathrm{p}<0.001$; therefore, multivariate tests are reported $(\varepsilon=0.93)$. The results showed that PSS significantly decreased, $\mathrm{V}=0.69, \mathrm{~F}(2,271)=295.3, \mathrm{p}<0.001, \omega^{2}=0.38$.

2. Maulchy's test indicated that the assumption of sphericity had been violated: $\chi^{2}(2)=50.17, \mathrm{p}<0.001$; therefore, multivariate tests are reported $(\varepsilon=0.85)$. The results showed that GAD-7 scores significantly decreased, $\mathrm{V}=0.63, \mathrm{~F}(2,271)=230.02, \mathrm{p}<0.001, \omega^{2}=0.44$.

3 . Maulchy's test indicated that the assumption of sphericity had been violated: $\chi^{2}(2)=107.41, \mathrm{p}<0.001$; therefore, multivariate tests are reported $(\varepsilon=0.75)$. The results showed that PHQ-9 scores significantly decreased, $\mathrm{V}=0.50, \mathrm{~F}(2,271)=136.52, \mathrm{p}<0.001, \omega^{2}=0.27$.

\section{DISCUSSION}

The aim of this investigation was to evaluate the feasibility and effectiveness of an online mindfulness course for perceived stress, anxiety and depression. Earlier studies had shown promise, but had not examined the change in these variables in a non-clinical sample using an online mindfulness course based directly on MBSR and MBCT courses. This study was also the first, to our knowledge, to evaluate the amount of practice as a mediator of change with a mindfulness course delivered in this mode.

The people choosing to use the course in this mode of delivery appear to be finding it helpful. That the levels of negative emotion reduced significantly on completion of the online mindfulness course and further decreased at 1 month follow-up is suggestive of significant improvements. People with higher levels of stress, anxiety and depression self-reported less practice and took longer to complete the course. A longer course time predicted less of a change in stress, anxiety and depression. More mindfulness practice significantly improved stress, anxiety and depression outcome when accounting for baseline severity.

The current study does have limitations. First, there is no control comparison so although negative mood decreases significantly, we cannot be sure that the course was responsible. There may be other reasons why stress, anxiety and depression decreased over this period of time; it may be due to regression to the mean. The sample consisted of people who completed the course and follow-up, so there may be bias; however, the sample 
did include people who had not finished the course but still logged on to report their follow-up.

Second, clinical status was not assessed. Participants who were feeling more stressed, depressed and anxious at baseline may have been suffering from particular disorders, making them less motivated, therefore practicing less and taking longer to complete the course. One of the benefits of this online course is anonymity, so the only data requested are date of birth, gender, measures and self-report practice. The current research suggests that a self-referred (and therefore perhaps more motivated) non-clinical sample of participants who are 'highly stressed', 'moderately depressed' and 'moderately anxious' do benefit from the course, but we do not yet know how beneficial the course would be for samples with particular disorders or clinical symptoms or who are referred by clinicians. Self-referral and willingness to pay for a course may make these study outcomes less generalisable for the UK where people do not have to pay, but more generalisable to other health systems in the world.

Finally, self-reported practice may not be accurate. That the course can be taken at a preferred pace is beneficial, but means that the weekly reported practice levels may not reflect how much actual practice is being completed; for example, the total amount of practice may be higher for those who completed the course over a longer time period. In future, it might be beneficial to ask more specifically about whether practice was completed in minutes or a number of days, or to collect the data for when participants completed practice logs so that the time they spent on each week could be determined. This information was unavailable at the time of this investigation but is something which could be implemented in future.

Despite these limitations, it is encouraging that the changes in perceived stress, anxiety and depression are comparable to other online interventions, to mindfulness courses delivered in person and to IAPT interventions. This result is surprising as having group and therapist interaction during a course is expected to be an important factor in recovery. Yet the comparative large effect sizes may be actually due to the mode of delivery, whereby those participants signing up to an online course of their own accord prefer to access the mindfulness exercises from their homes or other familiar surroundings, enabling them to use the learned skills in situations where they might be more readily recalled and more effectively used. That there was a further significant decrease in negative mood 1 month on is encouraging and suggests continued use of the skills learnt.

Participants who were more stressed, depressed and anxious at baseline tended to practice less and take more time to complete the course. These participants may have been less motivated and less able to complete the exercises in the weekly time frames because of their low mood. This result contrasts with our previous preliminary study where participants who were more stressed tended to practice more. It is unclear why the result differs from the previous finding, except that these are two different samples, recruited at different time points and with different advertising. When the second sample was signing up to the course, the website was more popular, so perhaps more people tried it who actually felt too low to complete the course or do as much practice as their healthier counterparts. However, despite the lower levels of practice, these participants had outcomes comparable to those who practiced more.

In conclusion, the results for the effectiveness and feasibility of this online mindfulness course look promising. The mode of delivery seems to be an acceptable way of completing a mindfulness course and appears to decrease stress, anxiety and depression. That the effects shown compare to those found for mindfulness courses delivered in person shows potential for future internet interventions delivered to those otherwise unable to receive helpful interventions. Further research is warranted to investigate the mechanisms of change, to examine the change compared to a control group and compared to face-to-face mindfulness interventions and to explore potential benefits for other populations.

Acknowledgements The authors would like to thank Richard Latham and Scott King of Wellmind Media Ltd, for their help in developing the online intervention, and Paul Bristow of the Mental Health Foundation, for his continued support.

Contributors EC and MW contributed to the first draft, which was written by AK. The intervention was developed by MW, SK and RL. AK, EC and MW designed the analysis plan, and AK analysed the data. All authors critically revised the manuscript and approved the final version. AK is the guarantor.

Funding This research received no specific grant from any funding agency in the public, commercial or not-for-profit sectors.

Competing interests The Mental Health Foundation receives a fee from the intervention. None of the authors receive any payment personally; there are no other relationships or activities that could appear to have influenced the submitted work. The data were handled and analysed securely and confidentially by AK at the University of Oxford.

Provenance and peer review Not commissioned; externally peer reviewed.

Data sharing statement There is no additional unpublished data, except for the anonymous raw data which will be uploaded to Dryad.

Open Access This is an Open Access article distributed in accordance with the Creative Commons Attribution Non Commercial (CC BY-NC 3.0) license, which permits others to distribute, remix, adapt, build upon this work noncommercially, and license their derivative works on different terms, provided the original work is properly cited and the use is non-commercial. See: http:// creativecommons.org/licenses/by-nc/3.0/

\section{REFERENCES}

1. Singleton N, Bumpstead R, O'Brien M, et al. Psychiatric morbidity among adults living in private households, 2000. Int Rev Psychiatry 2003;15:65-73.

2. Ebmeier KP, Donaghey C, Steele JD. Recent developments and current controversies in depression. Lancet 2006;367:153-67.

3. Mukuria C, Brazier J, Barkham M, et al. Cost-effectiveness of an improving access to psychological therapies service. Br J Psychiatry 2013;202:220-7.

4. Wilhelm K, Parker G, Dewhurst-Savellis J, et al. Psychological predictors of single and recurrent major depressive episodes. $J$ Affect Disord 1999;54:139-47.

5. Davey GL, Tallis F, Capuzzo N. Beliefs about the consequences of worrying. Cognitive Ther Res 1996;20:499-520. 
6. Brosschot JF, Gerin W, Thayer JF. The perseverative cognition hypothesis: a review of worry, prolonged stress-related physiological activation, and health. J Psychosom Res 2006;60:113-24.

7. Segerstrom S, Miller G. Psychological stress and the human immune system: a meta-analytic study of 30 years of inquiry. Psychol Bull 2004:130:601-30.

8. Pine DS, Cohen P, Johnson JG, et al. Adolescent life events as predictors of adult depression. J Affect Disord 2002;68: 49-57.

9. Hammen C. Stress and depression. Annu Rev Clin Psychol 2005;1:293-319.

10. Kabat-Zinn J. An outpatient program in behavioral medicine for chronic pain patients based on the practice of mindfulness meditation: theoretical considerations and preliminary results. Gen Hosp Psychiatry 1982;4:33-47.

11. Kabat-Zinn J. Full catastrophe living : using the wisdom of your body and mind to face stress, pain, and illness. New York, NY: Delacorte Press, 1990:453.

12. Segal ZV, Williams JMG, Teasdale JD. Mindfulness-based cognitive therapy for depression: a new approach to preventing relapse. New York: Guilford Press, 2002:351.

13. Grossman P, Niemann L, Schmidt S, et al. Mindfulness-based stress reduction and health benefits: a meta-analysis. J Psychosom Res 2004;57:35-43.

14. Shapiro SL, Oman D, Thoresen CE, et al. Cultivating mindfulness: effects on well-being. J Clin Psychol 2008;64:840-62.

15. Piet J, Wurtzen $H$, Zachariae R. The effect of mindfulness-based therapy on symptoms of anxiety and depression in adult cancer patients and survivors: a systematic review and meta-analysis. J Consult Clin Psychol 2012;80:1007-20.

16. Teasdale JD, Segal ZV, Williams JMG, et al. Prevention of relapse/ recurrence in major depression by mindfulness-based cognitive therapy. J Consult Clin Psychol 2000;68:615-23.

17. Ma HS, Teasdale JD. Mindfulness-based cognitive therapy for depression: replication and exploration of differentia relapse prevention effects. J Consult Clin Psychol 2004;72: 31-40.

18. Barnhofer T, Crane C, Hargus E, et al. Mindfulness-based cognitive therapy as a treatment for chronic depression: a preliminary study. Behav Res Ther 2009;47:366-73.

19. Hofmann SG, Sawyer AT, Witt AA, et al. The effect of mindfulnessbased therapy on anxiety and depression: a meta-analytic review. J Consult Clin Psychol 2010;78:169-83.

20. Carmody J, Baer RA. Relationships between mindfulness practice and levels of mindfulness, medical and psychological symptoms and well-being in a mindfulness-based stress reduction program. $J$ Behav Med 2008;31:23-33. p11.

21. Carmody J, Baer RA, Lykins LBE, et al. An empirical study of the mechanisms of mindfulness in a mindfulness-based stress reduction program. J Clin Psychol 2009;65:613-26.

22. Epel E, Daubenmier J, Moskowitz JT, et al. Can meditation slow rate of cellular aging? Cognitive stress, mindfulness, and telomeres. Ann NY Acad Sci 2009;1172:34-53.

23. Chiesa A, Serretti A. Mindfulness-based stress reduction for stress management in healthy people: a review and meta-analysis. $J$ Altern Complement Med 2009;15:593-600.

24. Kuyken W, ed. Mindfulness Training in the UK. 41st Annual European Association for Behavioural and Cognitive Therapies (EABCT) Conference. Reykjavik, Iceland, 2011.

25. Finucane A, Mercer S. An exploratory mixed methods study of the acceptability and effectiveness of mindfulness-based cognitive therapy for patients with active depression and anxiety in primary care. BMC Psychiatry 2006;6:14

26. Beattie A, Shaw A, Kaur S, et al. Primary-care patients' expectations and experiences of online cognitive behavioural therapy for depression: a qualitative study. Health Expect 2009;12:45-59.

27. Clarke G, Kelleher C, Hornbrook M, et al. Randomized effectiveness trial of an internet, pure self-help, cognitive behavioral intervention for depressive symptoms in Yyung adults. Cognitive Behav Ther 2009;38:222-34.

28. Powell J, Hamborg T, Stallard N, et al. Effectiveness of a web-based cognitive-behavioral tool to improve mental well-being in the general population: randomized controlled trial. $J$ Med Internet Res 2013;15:e2.

29. Zetterqvist K, Maanmies J, Ström L, et al. Randomized controlled trial of internet-based stress management. Cognitive Behav Ther 2003;32:151-60.

30. Eisen KP, Allen GJ, Bollash M, et al. Stress management in the workplace: a comparison of a computer-based and an in-person stress-management intervention. Comput Hum Behav 2008;24:486-96.
31. Spek V, Cuijpers P, Nyklicek I, et al. Internet-based cognitive behaviour therapy for symptoms of depression and anxiety: a meta-analysis. Psychol Med 2007;37:319-28.

32. Holländare $\mathrm{F}$, Johnsson $\mathrm{S}$, Randestad M, et al. Randomized trial of internet-based relapse prevention for partially remitted depression. Acta Psychiatr Scand 2011:124:285-94.

33. Bockting C, Kok G, Kamp L, et al. Disrupting the rhythm of depression using mobile cognitive therapy for recurrent depression: randomized controlled trial design and protocol. BMC Psychiatry 2011;11:12.

34. Christensen $\mathrm{H}$, Griffiths KM, Jorm AF. Delivering interventions for depression by using the internet: randomised controlled trial. $B M J$ 2004;328:265.

35. Christensen H, Griffiths KM, Mackinnon AJ, et al. Online randomized controlled trial of brief and full cognitive behaviour therapy for depression. Psychol Med 2006;36:1737-46.

36. Williams AD, Blackwell SE, Mackenzie A, et al. Combining imagination and reason in the treatment of depression: a Randomized controlled trial of internet-based cognitive-bias modification and internet-CBT for depression. J Consult Clin Psychol 2013;81:793-9.

37. Morledge T, Allexandre D, Fox E, et al. Feasibility of an online mindfulness program for stress management-a randomized, controlled trial. Ann Behav Med 2013;46:137-48.

38. Monshat K. Design and refinement of the MATE program: mindful awareness training and education. How do young people understand and practise mindfulness? University of Melbourne, 2012.

39. Gluck T, Maercker A. A randomized controlled pilot study of a brief web-based mindfulness training. BMC Psychiatry 2011;11:175.

40. Wolever RQ, Bobinet $\mathrm{KJ}$, McCabe $\mathrm{K}$, et al. Effective and viable mind-body stress reduction in the workplace: a randomized controlled trial. J Occup Health Psychol 2012;17:246-58.

41. Krusche A, Cyhlarova E, King S, et al. Mindfulness online: a preliminary evaluation of the feasibility of a web-based mindfulness course and the impact on stress. BMJ Open 2012;2:e000803.

42. Allexandre D, Neuman A, Hunter J, et al. Efficacy of an 8-week online mindfulness stress management program in a corporate call center. Portland, Oregon, USA: International Research Congress on Integrative Medicine and Health, 2012.

43. Ljótsson B, Hedman E, Andersson E, et al. Internet-delivered exposure-based treatment vs. stress management for irritable bowel syndrome: a randomized trial. Am J Gastroenterol 2011;106: 1481-91.

44. Greeson JM. Mindfulness research update: 2008. Complement Health Pract Rev 2009;14:10-18.

45. Quintana M, Rivera O. Mindfulness training online for stress reduction, a global measure. Annu Rev Cybertherapy Telemed 2012 2012;181:143

46. Baer RA, Carmody J, Hunsinger M. Weekly change in mindfulness and perceived stress in a mindfulness-based stress reduction program. Jl Clin Psychol 2012;68:755-65.

47. Cohen S, Kamarck T, Mermelstein R. A global measure of perceived stress. J Health Soc Behav 1983;24:385-96.

48. Spitzer RL, Kroenke K, Williams JBW, et al. A brief measure for assessing generalized anxiety disorder: the GAD-7. Arch Intern Med 2006;166:1092-7.

49. Kroenke K, Spitzer RL, Williams JBW. The PHQ-9. J Gen Intern Med 2001;16:606-13.

50. Dobkin PL. Mindfulness-based stress reduction: what processes are at work? Complement Ther Clin Pract 2008:14:8-16.

51. Löwe B, Decker O, Müller S, et al. Validation and standardization of the generalized anxiety disorder screener (GAD-7) in the general population. Med Care 2008;46:266-74.

52. Kroenke K, Spitzer RL, Williams JBW, et al. The Patient Health Questionnaire Somatic, Anxiety, and Depressive Symptom Scales: a systematic review. Gen Hosp Psychiatry 2010;32:345-59.

53. Kroenke K, Spitzer RL, Williams JBW, et al. Anxiety disorders in primary care: prevalence, impairment, comorbidity, and detection Ann Intern Med 2007;146:317-25.

54. Bian C, Li C, Duan Q, et al. Reliability and validity of patient health questionnaire: depressive syndrome module for outpatients. Sci Res Essays 2011;6:287-2.

55. Gilbody S, Richards D, Brealey S, et al. Screening for depression in medical settings with the patient health Qqestionnaire (PHQ): a diagnostic meta-analysis. J Gen Intern Med 2007;22:1596-602. English.

56. Hartmann M, Kopf S, Kircher C, et al. Sustained effects of a mindfulness-based stress-reduction intervention in type 2 diabetic patients: design and first results of a randomized controlled trial (the Heidelberger Diabetes and Stress-Study). Diabetes Care 2012;35:945-7. 
57. Kearney DJ, McDermott K, Malte C, et al. Association of participation in a mindfulness program with measures of PTSD, depression and quality of life in a veteran sample. J Clin Psychol 2012:68:101-16.

58. Cohen S, Williamson G. Perceived stress in a probability sample of the United States. In: Spacapan S, Oskamp S, eds. The social psychology of health: Claremont symposium on applied social psychology, 1998:31-67.

59. Shapiro SL, Carlson LE, Astin JA, et al. Mechanisms of mindfulness. $J$ Clin Psychol 2006;62:373-86.
60. Löwe B, Spitzer RL, Williams JBW, et al. Depression, anxiety and somatization in primary care: syndrome overlap and functional impairment. Gen Hosp Psychiatry 2008;530:191-9.

61. Farid A. Effect of acceptance-based behavior therapy on severity of symptoms, worry and quality of life in women with generalized anxiety disorder. Iran J Psychiatry Behav Sci 2012;6:23-32.

62. Main NA, Elliot SA, Brown JSL. Comparison of three different approaches used in large-scale stress workshops for the general public. Behav Cogn Psychother 2005;33:299-309. 